\title{
CAS: 50 years of digital art
}

\author{
Sean Clark \\ De Montfort University \\ Leicester, UK \\ seanc@cuttlefish.com
}

\author{
Nick Lambert \\ Ravensbourne \\ North Greenwich, London, UK \\ n.lambert@rave.ac.uk
}

\section{INTRODUCTION}

Founded in 1968, the Computer Arts Society has long explored such ideas. From early artworks using cybernetics, to algorithmic systems involving evolution and growth, to artists using the blockchain, immersive technologies, $\mathrm{Al}$ and robotics, the Society has provided a forum for the latest thinking in the arts and computing.

\section{THE COMPUTER ARTS SOCIETY}

The Computer Arts Society was founded in London by Alan Sutcliffe, John Lansdown and George Mallen following an initial idea at the IFIP Conference in 1968. The group had its first exhibition, 'Event One', at the Royal College of Art in 1969, followed by later shows at Computer Graphics 70, and 'Interact' at Edinburgh in 1973. Sutcliffe was particularly interested in computer music; Lansdown in computer-based architecture and also dance and performance; and Mallen in cybernetics and interaction.

Though based in the UK, this group had an international reach on both sides of the Atlantic and also served as a point of contact between many other digital arts researchers and artists from the late 60 s to early $80 \mathrm{~s}$. It hosted several early and important exhibitions but the group was most notable for acting as a link, which was in large measure due to the diligence and wide-ranging intelligence of Gustav Metzger, the first editor of its journal PAGE, and most famous for his approach to Auto-Destructive Art.

Metzger was involved with the group from its inception until late 1972 and spent considerable time researching contemporary accounts of computer art, technology and the social effects of the computer. In this process he established an identity for CAS that combined appreciation for the technological advances then occurring, with debates around the aesthetic issues raised by the computer in art, and a social awareness of the role of computer technology in the "military-industrial complex" that Eisenhower had named it in his outgoing speech.

CAS was in many ways of its time, but the articles and debates recorded in PAGE reveal a very rich and complex digital arts scene even at that early stage. Such a scene did not spring up ex nihilo nor in a vacuum, and we also see its antecedents emerging at exhibitions including Cybernetic Serendipity.

The CAS had active chapters in the USA and the Netherlands; and its involvement in Bit International (1969) demonstrates a strong interest in Central and Eastern Europe. Moreover, early computer arts pioneers in Japan - the Computer Technique Group - and Brazil - Waldemar Cordeiro - also engaged with CAS.

Now, fifty years later, an exhibition titled "CAS: 50 Years of Digital Art" is being organised by Sean Clark on behalf of CAS and Interact Digital Arts. Alongside this there will be a panel of significant artists from all periods of CAS activity and discussions about the future of the computer arts.

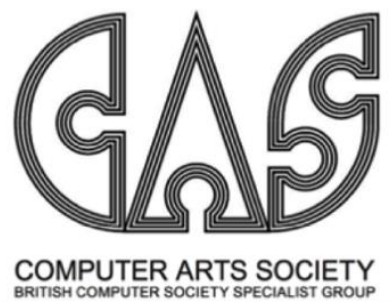

Figure 1: The CAS at 50. 